\title{
Síndrome de Burnout em gerentes da Estratégia de Saúde da Família
}

\author{
Burnout Syndrome in Family Health Strategy Managers
}

Alice Mariz Porciuncula (http://orcid.org/0000-0002-2994-8327) ${ }^{1}$

Sandra Aparecida Venâncio (http://orcid.org/0000-0002-1439-2960) ${ }^{1}$

Cosme Marcelo Furtado Passos da Silva (https://orcid.org/0000-0001-7789-1671) ${ }^{1}$

${ }^{1}$ Escola Nacional de Saúde Publica Sérgio Arouca, Fundação Oswaldo Cruz. R. Leopoldo Bulhões 1480, Manguinhos. 21041-210 Rio de Janeiro RJ Brasil. alicemarizpresf@gmail.com

\begin{abstract}
This paper analyzed the Burnout Syndrome (BS) among the managers of the Family Health Strategy (ESF) in the city of Rio de Janeiro and its associations with factors that influence the presence/absence of BS among these professionals. This is a descriptive study that used data from a questionnaire consisting of two parts: 1) manager profile and factors that could influence the presence of Burnout; 2) Maslach Burnout Inventory. The return rate was $63.5 \%$ (143) of the 225 questionnaires sent. The ESF managers are generally nurses (68.6\%), young (63.6\% under 39 years) female $(76.9 \%)$, who have acted as managers for less than 5 years (85.2\%). A BS presence was identified in $11.2 \%$ of the managers. The factors of an organizational nature were those that obtained the highest number of variables with an association. These data point to the need to make changes in the organizational practices of services and changes in work processes. Further studies on these issues can contribute to this.
\end{abstract}

Key words Burnout, Primary Health Care, Health Manager
Resumo Este artigo analisou a Síndrome de Burnout (SB) entre os gerentes da Estratégia de Saúde da Família (ESF) no Município do Rio de Janeiro e suas associações entre os fatores que influenciam a presença/ausência da SB nesses profissionais. Com natureza descritiva, ele utilizou um questionário, composto de duas partes: 1) perfil do gerente e fatores que possam influenciar a presença de Burnout; 2) Inventário Maslach Burnout Inventory. A taxa percentual de retorno foi de 63,5\% (143) dos 225 enviados. Os gerentes da ESF são em geral, enfermeiros (68,6\%), jovens (74,5\% até 39 anos), do sexo feminino $(76,9 \%)$ e que atuam na gerência há menos de 5 anos (85,2\%). A presença da SB foi identificada em 11,2\% dos gerentes. Os fatores de natureza organizacional foram os que obtiveram maior número de variáveis com associação. Esses dados apontam para necessidade de realização de mudanças nas práticas organizativas de serviços $e$ de mudanças nos processos de trabalho. A realização de outros estudos, que aprofundem estas questões, pode contribuir neste sentido.

Palavras-chave Burnout, Atenção Primária à Saúde, Gestor de saúde 


\section{Introdução}

O estudo apresentado analisou a presença da Síndrome de Burnout (SB) entre os gerentes da Estratégia de Saúde da Família (ESF) no Município do Rio de Janeiro. O cargo de gerente profissional foi instituído neste Município no bojo da Reforma do Modelo de Gestão da Atenção Primária à Saúde (APS) realizada pela Secretaria Municipal de Saúde (SMS), em $2009^{1}$, através da incorporação de contratos de Gestão entre a SMS e as Organizações Sociais ${ }^{2,3}$. Ao gerente cabe a tarefa de coordenar os meios e os processos para que a organização cumpra com sua finalidade $e^{4}$. Ele se diferencia do papel do gestor em saúde, a quem cabe a responsabilidade de dirigir o sistema de saúde nas diferentes esferas de governo ${ }^{5}$.

$\mathrm{O}$ avanço na distinção conceitual entre essas funções não veio acompanhado de definições claras sobre o papel e as atribuições dos gerentes ${ }^{6}$, embora sua atividade seja essencial para o processo de produção em saúde ${ }^{7}$. Aliados à forte pressão pelo alcance de resultados em curto prazo de tempo, aos baixos salários e ao número insuficiente de profissionais, o desenvolvimento desta função pode gerar frustração, angústia, fracasso e esgotamento, levando ao adoecimento físico ${ }^{8}$.

Entre outros aspectos, o stress laboral crônico proveniente da desilusão, do desânimo e de uma intensa frustração com o trabalho, no qual o trabalhador antes extremamente envolvido com o serviço e com os clientes, perde energia e desiste, constitui uma das principais características da $\mathrm{SB}^{9}$. Sua presença entre os trabalhadores pode influenciar na qualidade da atenção prestada ${ }^{10-12}$, já que o bem-estar e satisfação profissional são fatores importantes para que o mesmo exerça suas funções com melhor eficiência.

Maslach et al. ${ }^{13}$ estão dentre os autores que estudaram a síndrome de Burnout com grande frequência. Para eles, essa síndrome decorre da presença de três elementos: exaustão emocional, despersonalização e baixa realização profissional ${ }^{13}$.

A exaustão emocional é sua manifestação mais óbvia, envolvendo fatores organizacionais e individuais. É uma resposta ao estresse crônico provocado pelo trabalho, que acompanha o sentimento de não possuir recursos emocionais para lidar com as situações estressoras ${ }^{13,14}$.

A despersonalização está associada ao endurecimento afetivo do profissional, demonstrada através de cinismo, indiferença e ironia diante do sujeito com ou para quem se atua, como forma de evitar o envolvimento com as pessoas ${ }^{13,14}$.

A diminuição da realização profissional está ligada à descrença ao valor de sua atividade la- boral, baixa autoestima, insatisfação e desmotivação, referindo-se à autoavaliação negativa do profissional quanto à qualidade do trabalho executado. O sujeito se torna infeliz consigo e insatisfeito com seus feitos no trabalho ${ }^{14,15}$.

Além das características pessoais, aspectos relacionados às más condições laborais, decorrentes das recentes transformações no mundo do trabalho, expressas entre outros aspectos pela restruturação produtiva, demissões em massa, precarização e exigência crescente dos trabalhadores são descritos como os principais determinantes da Síndrome ${ }^{13}$.

Em alguns países o diagnóstico de Burnout permite ao trabalhador receber uma compensação financeira, além de aconselhamento, de psicoterapia e de reabilitação. Em outros, porém, não há seu reconhecimento como doença provocada pelo trabalho ${ }^{16}$. No Brasil, os Ministérios da Saúde e o da Previdência Social, consideram a SB como doença ocupacional relacionada ao traba$1 \mathrm{ho}^{17,18}$. Todavia, conforme aponta Zorzanelli et al. ${ }^{19}$, ela permanece pouco conhecida nos âmbitos médicos e nos previdenciários.

Estudos recentes sobre a presença da SB na ESF identificaram sua presença entre os Agentes comunitários de Saúde $(29,3 \%)^{20}$ e entre os profissionais da APS $(7 \%)^{21}$ na cidade de Aracaju, em Sergipe.

Em nosso trabalho, que busca identificar fatores associados ao desenvolvimento de $\mathrm{SB}$ entre os gerentes da ESF do Município do Rio de Janeiro, contribuiria para a reflexão sobre o cargo de gerente e os processos nos quais está envolvido. Desse modo, somos levados a pensar em novas maneiras de prevenir e de cuidar do adoecimento desse profissional, assim como suas consequências.

\section{Métodos}

Trata-se de um estudo de natureza descritiva, de corte transversal, realizada em todo território do município do Rio de Janeiro. Os sujeitos da pesquisa foram os gerentes atuantes em unidades de saúde com ESF no município no momento de seu desenvolvimento. Excluídos aqueles que atuam em unidades de saúde sem a presença da ESF, além dos que não responderam o questionário.

O questionário utilizado foi composto de duas partes: uma contendo questões que visavam traçar o perfil dos gerentes entrevistados e identificar fatores que possam influenciar a presença ou ausência de SB, e outra, contendo o inventário Maslach Burnout Inventory (MBI). 
A primeira parte envolveu 39 questões referentes às características pessoais e profissionais dos participantes (idade, sexo, estado civil, filhos, profissão, atuação em outro emprego, qualificação, tempo de experiência, personalidade, aparecimento de sintomas), as das unidades (número de equipes, presença de outro gerente, condições físicas, frequência de conflitos e presença de violência armada no território de atuação) e possíveis agentes causadores ou protetores de Burnout (prazos, responsabilidades, expectativas da comunidade, demandas, carga horária, trabalho fora do horário, valorização, estabilidade, ascensão, remuneração, apoio institucional, autonomia, instrumentos de apoio e respeito para tomada de decisões). Estas variáveis foram escolhidas considerando a possível relação com a SB demonstrada em diversos estudos quanto ao tema ${ }^{13,14,22}$.

O MBI, segunda parte do questionário, foi criado por Maslach e Jackson ${ }^{15} \mathrm{em} 1981$ para avaliar a SB. Optou-se por essa escala por seu amplo uso em estudos sobre o tema no mundo e por se tratar de material já validado no Brasil. Cerca de 90\% dos estudos sobre SB utilizaram o MBI ou alguma adaptação do mesmo ${ }^{14}$.

A Escala contém três dimensões para avaliar a relação do trabalhador com seu trabalho: Exaustão Emocional (9 questões), Realização Profissional (8 questões) e Despersonalização (5 questões). Para sua utilização na pesquisa, adotou-se o questionário validado por Tamayo e Tróccoli ${ }^{10}$. Este instrumento contém 22 questões, com 5 possibilidades de respostas, que recebem a pontuação da seguinte forma: "Nunca" - 1 ponto, "Algumas vezes no ano" -2 pontos, "Algumas vezes no mês" - 3 pontos, "Algumas vezes na semana" -4 pontos e "Diariamente" -5 pontos. As propriedades psicométricas da escala possuem consistência interna das três dimensões satisfatória, apresentando um alfa de Cronbach que vai de 0,71 a $0,90^{23}$. Sendo assim, o escore atribuído a cada indivíduo variava entre as dimensões de acordo com o número de questões e a pontuação atribuída por cada entrevistado às perguntas: Exaustão Emocional (9 a 45); Realização Profissional (8 a 40) e Despersonalização (5 a 25).

Conforme orientam os criadores do inventário, avaliamos cada dimensão individualmen$\mathrm{te}^{15}$. Estatisticamente, os pontos de corte foram determinados como "baixo" "moderado" e "alto", baseados nos tercis baixo, médio e alto da distribuição da pontuação, assim como recomenda o manual do $\mathrm{MBI}^{16}$ descritos na Tabela 1 .

Os questionários foram distribuídos presencialmente ou através de envio online. A versão online, idêntica ao questionário de papel, foi construída com o dispositivo Google Drive, e, objetivou ampliar a participação do público alvo, tendo em vista a dificuldade observada entre os gerentes de disponibilizar tempo para seu preenchimento. Para reduzir as perdas foram realizados contatos telefônicos com os gerentes e o reenvio dos questionários por até quatro vezes. No momento da pesquisa havia 225 gerentes atuantes na ESF no MRJ, tendo sido o instrumento enviado a todos. O retorno foi de $63,5 \%$, ou seja, um total de 143 participantes.

O SPSS foi o software utilizado para analisar os dados, distribuídos em tabela com frequências (absolutas e relativas) e, em medidas de resumo (mínimo, máximo, média, mediana, desvio padrão, variância e coeficiente de variação). As associações foram avaliadas através do teste de independência Chi-quadrado $\left(c^{2}\right)$ e, quando necessário, teste exato de Fisher. Foi adotado o nível de significância de 5\%. Por não se tratar de amostra probabilística não se pretende generalizar os achados deste estudo, mas apenas testar associação entre as variáveis na amostra.

O estudo foi submetido e aprovado pelos Comitês de Ética em Pesquisa da Escola Nacional de Saúde Pública Sergio Arouca (ESNP) e da Secretaria Municipal de Saúde do Rio de Janeiro e, o Termo de consentimento livre e esclarecido apresentado aos participantes e tiveram sua anuência.

\section{Resultados}

Os gerentes das unidades de ESF são em geral jovens de até 39 anos $(74,5 \%)$, do sexo feminino $(76,9 \%)$, quase a metade é casada $(49,7 \%)$ e a maioria tem filhos $(53,8 \%)$. A enfermagem é a profissão prevalente $(68,6 \%)$ e o trabalho como gerente o único vínculo empregatício $(73,4 \%)$. A experiência com a gerência é recente, entre 2 e 5 anos (50\%), sendo que $35,2 \%$ desenvolvem esta atividade há menos de dois anos. Atuam em área onde há presença de violência armada 55,9\% (Tabela 2).

A presença da SB, onde o indivíduo apresenta as três dimensões em nível crítico ${ }^{14,23}$, foi identificada em $11,2 \%$ dos gerentes.

A Tabela 3 aponta os achados referentes a cada dimensão da SB encontrados dentre os participantes. Destes, $29,4 \%$ apresentam a dimensão exaustão emocional em nível alto, $25,2 \%$ despersonalização em níveis altos e $32,8 \%$ realização profissional em nível crítico.

Ao contrário de outros estudos que realizam cruzamentos de dados entre as variáveis e as dimensões separadamente, optamos por uma 
Tabela 1. Pontos de corte para diagnóstico das Dimensões da Síndrome de Burnout segundo tercis identificados.

\begin{tabular}{lllcc}
\hline \multirow{2}{*}{\multicolumn{1}{c}{ Dimensões }} & \multicolumn{1}{c}{ Questões } & \multicolumn{3}{c}{ Nível } \\
\cline { 3 - 5 } & \multicolumn{1}{c}{ Baixo } & Médio & Alto \\
\hline Exaustão emocional & $1,2,3,6,8,13,14$ 16 e 20 & $<24$ & $24-31$ & $>31$ \\
Despersonalização & $5,10,11,15$ e 22 & $<9$ & $09-12$ & $>12$ \\
Realização profissional & $4,7,9,12,17,18,19$ e 21 & $<32$ & $32-35$ & $>35$ \\
\hline
\end{tabular}

Tabela 2. Distribuição absoluta e proporcional dos gerentes de ESF segundo Perfil.

\begin{tabular}{|c|c|c|}
\hline & $\mathrm{n}^{*}$ & $\%$ \\
\hline Idade & 141 & 100,0 \\
\hline 20 a 29 anos & 30 & 21,3 \\
\hline 30 a 39 anos & 75 & 53,2 \\
\hline 40 a 49 anos & 23 & 16,3 \\
\hline 50 ou mais anos & 13 & 9,2 \\
\hline Não responderam & 2 & - \\
\hline Sexo & 143 & 100,0 \\
\hline Feminino & 110 & 76,9 \\
\hline Masculino & 33 & 23,1 \\
\hline Estado civil & 143 & 100,0 \\
\hline Casado & 71 & 49,7 \\
\hline Divorciado & 16 & 11,2 \\
\hline Solteiro & 55 & 38,4 \\
\hline Viúvo & 1 & 0,7 \\
\hline Filhos & 143 & 100,0 \\
\hline Sim & 77 & 53,8 \\
\hline Não & 66 & 46,2 \\
\hline Profissão & 137 & 100,0 \\
\hline Enfermeira & 94 & 68,6 \\
\hline Dentista & 16 & 11,7 \\
\hline Assistente social & 7 & 5,1 \\
\hline Nutricionista & 6 & 4,4 \\
\hline Fisioterapeuta & 5 & 3,6 \\
\hline Psicólogo & 3 & 2,2 \\
\hline Farmacêutica & 2 & 1,5 \\
\hline Médica & 2 & 1,5 \\
\hline Fonoaudióloga & 1 & 0,7 \\
\hline Bióloga & 1 & 0,7 \\
\hline Não responderam & 6 & - \\
\hline Possui outro emprego & 143 & 100,0 \\
\hline Não & 105 & 73,4 \\
\hline Sim & 38 & 26,6 \\
\hline \multicolumn{3}{|l|}{$\begin{array}{l}\text { Tempo de experiência na } \\
\text { gerência }\end{array}$} \\
\hline$<2$ anos & 50 & 35,2 \\
\hline 2 anos $\mathrm{a}<5$ anos & 71 & 50,0 \\
\hline 5 anos ou mais & 21 & 14,8 \\
\hline $\begin{array}{l}\text { Atuação em área de violência } \\
\text { armada }\end{array}$ & 143 & 100,00 \\
\hline Não & 63 & 44,1 \\
\hline Sim & 80 & 55,9 \\
\hline
\end{tabular}

Tabela 3. Distribuição absoluta e proporcional quanto as Dimensões da Síndrome de Burnout encontrada nos gerentes da ESF.

\begin{tabular}{llcc}
\hline & & $\mathbf{n}$ & \% \\
\hline Exaustão & Baixo & 48 & 33,6 \\
emocional & Moderado & 53 & 37,0 \\
& Alto & 42 & 29,4 \\
Despersonalizaçãoo & Baixo & 48 & 33,6 \\
& Moderado & 59 & 41,2 \\
Realização & Alto & 36 & 25,2 \\
Profissional & Baixo & 47 & 32,8 \\
& Moderado & 50 & 35,0 \\
& Alto & 46 & 32,2 \\
\hline
\end{tabular}

combinação direta com os resultados quanto à presença/ausência de Burnout, uma vez que pretendemos identificar possíveis explicações para a síndrome em seu contexto total. Para facilitar a leitura e compreensão as variáveis explicativas foram agrupadas em temas comuns. São eles: características individuais, características das unidades de saúde e características organizacionais. Na Tabela 4, apresentamos aquelas em que encontramos associação.

Em relação às características individuais foram submetidas à combinação as variáveis: idade, sexo, estado civil, filhos, profissão, presença de outro emprego, experiência profissional, qualificação, personalidade (super envolvido, idealista, controlador e competitivo), presença de sintomas após assumir o cargo e os três sintomas mais encontrados (ansiedade, insônia e problemas com a pressão arterial).

Observou-se associação nos itens idade ( $\mathrm{p}$ $=0,043)$, ansiedade $(\mathrm{p}=0,019)$ e personalidade "super envolvido" $(p=0,050)$. A Síndrome estava presente entre os gerentes jovens (abaixo dos 40 anos) e entre aqueles que relatam o surgimento da ansiedade após terem assumido o cargo, um quarto apresentou a SB. Entre aqueles que não se consideram super envolvidos $30 \%$ foram identificados com SB, enquanto dentre os que se jul- 
Tabela 4. Variáveis explicativas associadas à Síndrome de Burnout em gerentes da ESF.

\begin{tabular}{|c|c|c|c|c|c|c|c|c|c|}
\hline & & & \multicolumn{2}{|c|}{ Total } & \multicolumn{2}{|c|}{$\begin{array}{c}\text { Sem } \\
\text { Burnout }\end{array}$} & \multicolumn{2}{|c|}{$\begin{array}{c}\text { Com } \\
\text { Burnout }\end{array}$} & \multirow[t]{2}{*}{$\mathbf{P}$} \\
\hline & & & $\mathbf{n}$ & $\%$ & $\mathrm{n}$ & $\%$ & $\mathbf{n}$ & $\%$ & \\
\hline \multirow{7}{*}{ 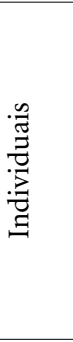 } & \multirow[t]{3}{*}{ Faixa etária } & 20 a 29 anos & 30 & 21,3 & 25 & 83,3 & 5 & 16,7 & 0,043 \\
\hline & & 30 a 39 anos & 75 & 53,2 & 64 & 85,3 & 11 & 14,7 & \\
\hline & & 40 anos ou mais & 36 & 25,5 & 36 & 100,0 & 0 & 0,0 & \\
\hline & \multirow{2}{*}{$\begin{array}{l}\text { Apresentou sintomas de } \\
\text { ansiedade após assumir } \\
\text { cargo de gestor }\end{array}$} & $\operatorname{Sim}$ & 24 & 26,1 & 18 & 75,0 & 6 & 25,0 & 0,019 \\
\hline & & Não & 68 & 73,9 & 109 & 91,6 & 10 & 8,4 & \\
\hline & \multirow{2}{*}{$\begin{array}{l}\text { Considera-se um } \\
\text { profissional superenvolvido }\end{array}$} & Sim & 133 & 93,0 & 120 & 90,2 & 13 & 9,8 & 0,050 \\
\hline & & Não & 10 & 7,0 & 7 & 70,0 & 3 & 30,0 & \\
\hline \multirow{4}{*}{ 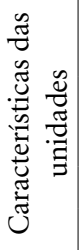 } & \multirow[t]{2}{*}{ Vivencia conflitos } & $\begin{array}{l}\text { Ocasionalmente/ } \\
\text { raramente/nunca }\end{array}$ & 48 & 33,6 & 47 & 97,9 & 1 & 2,1 & 0,014 \\
\hline & & Sempre/frequentemente & 95 & 66,4 & 80 & 84,2 & 15 & 15,8 & \\
\hline & \multirow{2}{*}{$\begin{array}{l}\text { Atua em área com presença } \\
\text { de violência armada }\end{array}$} & Sim & 80 & 55,9 & 66 & 82,5 & 14 & 17,5 & 0,007 \\
\hline & & Não & 63 & 44,1 & 61 & 96,8 & 2 & 3,2 & \\
\hline \multirow{22}{*}{ 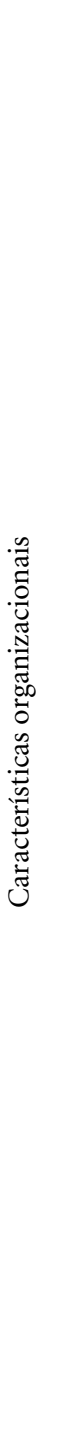 } & \multirow{2}{*}{$\begin{array}{l}\text { Considera número de } \\
\text { demandas solicitadas de } \\
\text { acordo com capacidade de } \\
\text { resposta }\end{array}$} & $\begin{array}{l}\text { Muito abaixo/abaixo/de } \\
\text { acordo }\end{array}$ & 67 & 46,9 & 66 & 98,5 & 1 & 1,5 & 0,001 \\
\hline & & Muito acima/acima & 76 & 53,1 & 61 & 80,3 & 15 & 19,7 & \\
\hline & \multirow{2}{*}{$\begin{array}{l}\text { Considera número de } \\
\text { responsabilidades de } \\
\text { acordo com capacidade de } \\
\text { resposta }\end{array}$} & Abaixo/de acordo & 70 & 49,0 & 67 & 95,7 & 3 & 4,3 & 0,010 \\
\hline & & Muito acima/acima & 73 & 51,0 & 60 & 82,2 & 13 & 17,8 & \\
\hline & \multirow[t]{2}{*}{$\begin{array}{l}\text { Considera prazos exigidos } \\
\text { suficientes }\end{array}$} & $\begin{array}{l}\text { Ocasionalmente/ } \\
\text { raramente/nunca }\end{array}$ & 114 & 79,7 & 98 & 86,0 & 16 & 14,0 & 0,032 \\
\hline & & Sempre/frequentemente & 29 & 20,3 & 29 & 100,0 & 0 & 0,0 & \\
\hline & \multirow{2}{*}{$\begin{array}{l}\text { Possui autonomia para } \\
\text { tomada de decisões }\end{array}$} & Grande/total & 79 & 55,3 & 76 & 96,2 & 3 & 3,8 & 0,002 \\
\hline & & Parcial/não possui & 64 & 44,7 & 51 & 79,7 & 13 & 20,3 & \\
\hline & \multirow[t]{2}{*}{$\begin{array}{l}\text { Julga instrumentos de } \\
\text { apoio }\end{array}$} & $\begin{array}{l}\text { Insuficientes/não } \\
\text { disponíveis }\end{array}$ & 87 & 60,8 & 72 & 82,8 & 15 & 17,2 & 0,004 \\
\hline & & Suficientes/indiferentes & 56 & 39,2 & 55 & 98,2 & 1 & 1,8 & \\
\hline & \multirow{4}{*}{$\begin{array}{l}\text { Sente-se apoiado } \\
\text { institucionalmente pela } \\
\text { Organização Social } \\
\text { contratante } \\
\text { Sente-se apoiado } \\
\text { institucionalmente pela } \\
\text { Coordenadoria de Ârea } \\
\text { Programática (suporte } \\
\text { territorial local) }\end{array}$} & $\begin{array}{l}\text { Ocasionalmente/ } \\
\text { raramente/nunca }\end{array}$ & 54 & 37,8 & 44 & 81,5 & 10 & 18,5 & 0,030 \\
\hline & & Sempre/frequentemente & 89 & 62,2 & 83 & 93,3 & 6 & 6,7 & \\
\hline & & $\begin{array}{l}\text { Ocasionalmente/ } \\
\text { raramente/nunca }\end{array}$ & 45 & 31,5 & 32 & 71,1 & 13 & 28,9 & $<0,001$ \\
\hline & & Sempre/frequentemente & 98 & 68,5 & 95 & 96,9 & 3 & 3,1 & \\
\hline & \multirow[t]{2}{*}{$\begin{array}{l}\text { Confia na Organização } \\
\text { Social }\end{array}$} & $\begin{array}{l}\text { Ocasionalmente/ } \\
\text { raramente/nunca }\end{array}$ & 36 & 25,2 & 28 & 77,8 & 8 & 22,2 & 0,015 \\
\hline & & Sempre/frequentemente & 107 & 74,8 & 99 & 92,5 & 8 & 7,5 & \\
\hline & \multirow{2}{*}{$\begin{array}{l}\text { Confia na Coordenadoria } \\
\text { de Área Programática } \\
\text { (suporte territorial local) }\end{array}$} & $\begin{array}{l}\text { Ocasionalmente/ } \\
\text { raramente/nunca }\end{array}$ & 41 & 28,7 & 31 & 75,6 & 10 & 24,4 & 0,001 \\
\hline & & Sempre/frequentemente & 102 & 71,3 & 96 & 94,1 & 6 & 5,9 & \\
\hline & \multirow[t]{2}{*}{ Sente-se valorizado } & $\begin{array}{l}\text { Ocasionalmente/ } \\
\text { raramente/nunca }\end{array}$ & 94 & 65,7 & 78 & 83,0 & 16 & 17,0 & 0,002 \\
\hline & & Sempre/frequentemente & 49 & 34,3 & 49 & 100,0 & 0 & 0,0 & \\
\hline & \multirow{2}{*}{$\begin{array}{l}\text { Acredita na possibilidade } \\
\text { de ascensão profissional }\end{array}$} & Parcialmente/não & 111 & 77,6 & 95 & 85,6 & 16 & 14,4 & 0,023 \\
\hline & & Sim & 32 & 22,4 & 32 & 100,0 & 0 & 0,0 & \\
\hline
\end{tabular}


gam super envolvidos somente 9,8\% apresentou Burnout.

No tocante às características das unidades foram empregadas as seguintes variáveis: número de equipes, presença de outro gerente, condições físicas, vivência de conflitos e presença violência armada no território de atuação. Foi encontrada relação apenas entre as duas últimas: vivência de conflitos $(\mathrm{p}=0,014)$ e presença de violência armada $(\mathrm{p}=0,007)$.

A situação de conflito é vivenciada (frequentemente/sempre) por 66,4\% dos gerentes. Destes $15,8 \%$ apresentaram a $\mathrm{SB}$, quantitativo sete vezes maior do que os que não vivenciam o conflito na mesma frequência. Foi de 17,8\% o percentual de $\mathrm{SB}$ entre aqueles gerentes que atuam (frequentemente/sempre) em área marcada por violência armada $(55,9 \%)$ e de $3,2 \%$ entre os que não atuam.

Nas características organizacionais foram testadas as seguintes variáveis: prazos, responsabilidades, demandas, valorização, ascensão, apoio institucional, autonomia, instrumentos de apoio, expectativa da comunidade, respeito para a tomada de decisões, carga horária de trabalho, trabalho fora do horário, estabilidade e remuneração. Apenas as quatro últimas variáveis não apresentaram associação com a SB.

Observou-se maior presença de Burnout no grupo de gerentes que acham que as demandas e responsabilidades exigidas estão acima/muito acima da sua capacidade de resposta e naqueles que consideram insuficiente o prazo para a realização das tarefas.

A maioria $(55,3 \%)$ dos gerentes identificou grande autonomia profissional para a realização de seu trabalho, o que é um aspecto importante para que o profissional possa desempenhá-lo a contento. Entre esses, a SB foi de 3,8\%; já entre aqueles que julgam não ter autonomia ou a descrevem como parcial, a presença da SB foi de $20,3 \%$. Os gerentes se sentem (frequentemente/ sempre) apoiados pela gestão $-62,5 \%$ pelas Organizações Sociais (OS) e 68,5\% pela Coordenadoria da área de planejamento (CAP) - bem como confiam nestas instâncias de organização (74,8\% nas OS e $71,3 \%$ nas CAP). A presença da Síndrome foi menor nestes grupos do que entre aqueles que não se sentem apoiados/não confiam.

Grandes impactos associativos foram encontrados no tocante a valorização profissional. No grupo que sempre/frequentemente se sente valorizado não foram encontrados casos de SB. Em contrapartida todos os casos da doença encontrados estavam dentre os que nunca, raramente ou ocasionalmente se sentem valorizados.
Apenas 22,4\% dos gerentes participantes acreditam na possibilidade de ascensão profissional, dentre estes nenhum desenvolveu a Síndrome.

\section{Discussão}

A presença da SB pode variar de acordo com a definição/metodologia adotada. Neste estudo, com base na definição de Ramirez et al. ${ }^{23}$, encontrouse o percentual de $11,2 \%$, semelhante ao verificado em outros estudos sobre a APS brasileira. Trindade et al. ${ }^{24}$ identificou o percentual de $6,9 \%$ de Burnout entre os profissionais da ESF em Santa Maria/RS; Silveira et al. encontraram 18\% entre os trabalhadores da APS de Porto Alegre/RS ${ }^{25}$. Já Silva et al. ${ }^{21}$ observou $7 \%$ dos profissionais da rede de APS com SB e, Poletto et al. ${ }^{26}$ identificou 9,5\% de Burnout entre os gestores municipais de saúde do estado de São Paulo. Estes achados nos levam a supor que os índices encontrados em gerentes da ESF do Rio de Janeiro podem estar acima da média nacional para este nível de atenção à saúde.

No entanto a existência de diversas escalas para identificação da síndrome e de indicações de pontos de corte dificulta esta comparação. Além disto, não foram identificados estudos nacionais e internacionais realizados sobre a Síndrome entre gerentes da APS.

É preciso compreender, ainda, os efeitos da presença da SB entre os gerentes para o funcionamento da ESF. A falta de energia para cumprir suas tarefas e para gerar os resultados necessários compromete o trabalho, o que acaba muitas vezes por levar esses gerentes a se afastarem ou abandonarem o serviço, ampliando a rotatividade nos cargos de gerência. Além disto, a pessoa com Burnout pode influenciar negativamente o ambiente de trabalho, causando conflitos e atrapalhando o desenvolvimento das tarefas ${ }^{13}$.

Quanto às variáveis explicativas, poucas características pessoais se associaram à $\mathrm{SB}$. Nossos achados reforçam o argumento de Maslach et al. ${ }^{13}$ que descreve a Burnout como um fenômeno mais social do que individual.

A idade, uma das poucas variáveis a apresentar associação positiva, é apontada na literatura como aspecto importante no surgimento da $\mathrm{SB}^{13,27}$. A existência da SB em pessoas relativamente jovens, como a que encontramos, é explicada nos estudos pela pouca experiência do trabalhador nesta faixa etária. Além de uma possível insegurança, é comum que os jovens possuam grande idealismo, assim como ansiedades e desejos, que geram altas expectativas quanto ao trabalho. Entretanto, a realidade encontrada im- 
pede estas expectativas de se realizarem, trazendo frustração, estresse e desânimo ${ }^{13,24}$.

Ainda não há consenso na literatura quanto à ligação entre SB e sexo. Alguns estudos relatam maior frequência em homens e outros, em mulheres $^{13}$. Neste estudo não foi identificada relação entre SB e sexo. Do mesmo modo, também não encontramos associação entre SB e profissão. Resultado semelhante já tinha sido descrito por Trindade et al. ${ }^{24}$. Este dado pode indicar que a síndrome pode estar mais associada às atribuições exercidas no cargo de chefia, do que com sua formação.

Embora diversos autores ${ }^{13,27}$ apontem que a existência de mais de um vínculo de trabalho pode ampliar as chances do desenvolvimento da SB, por aumentar a sobrecarga, neste estudo não foi encontrado ligação. Assim, como no estudo de Trindade et al. ${ }^{24}$ não se observou associação entre o tempo de experiência na APS e o surgimento da SB.

Apesar da qualificação dos profissionais de gestão em saúde ser indispensável para operar sistemas complexos como Sistema Único de Saú$\mathrm{de}^{4}$, não identificamos uma associação entre a qualificação e a presença da SB em gerentes, o que não descarta sua importância, pois a falta de qualificação, possivelmente, prejudica a efetividade dos profissionais. Como assinala Maslach et al. ${ }^{13} \mathrm{a}$ carga de trabalho fica desequilibrada não apenas quando há muitas tarefas a cumprir, mas também quando o trabalhador não possui as qualidades necessárias para realizar determinado serviço. $\mathrm{O}$ grau de envolvimento dos profissionais com o trabalho é descrito na literatura como fator que influencia na presença/ausência da SB. Em geral trabalhadores que apresentam em sua personalidade características de maior envolvimento, com extrema dedicação, motivados por seus ideais acabam trabalhando em demasia, chegando muitas vezes à exaustão e, se decepcionando quando não alcançam os resultados esperados ${ }^{13,28}$. Nossos achados não corroboram com esta visão; dentre os gerentes que se consideram super envolvidos o percentual de SB identificado é expressivamente menor do que dentre os que não se identificaram como tal. As razões desta diferença devem ser melhor entendidas por outros estudos.

A associação entre ansiedade e SB identificada neste estudo, merece atenção por parte da saúde do trabalhador. Muitos gerentes identificam o seu aparecimento após terem assumido o cargo de gerentes da ESF, o que nos leva a duas hipóteses: a ansiedade poderia induzir o adoecimento por Burnout ou dentre os sintomas trazidos pela $\mathrm{SB}$, nos gerentes de ESF, a ansiedade pode ser o mais frequente. De todo modo Maslach et al. ${ }^{13}$ evidenciam que a presença da Síndrome pode levar ao desenvolvimento de problemas relativos à saúde mental, dentre eles a ansiedade. No que tange às características das unidades, encontramos ligação com a SB em apenas dois pontos: vivência de conflitos e presença de violência armada. As condições físicas não se mostraram ligadas à $\mathrm{SB}$, assim como o tipo de unidade, número de equipes e presença de outro gerente ou diretor.

A existência de conflitos frequentemente produz sentimentos negativos de frustração e hostilidade, e reduz a possibilidade de suporte social ${ }^{13}$. A sensação de insuficiência trazida por esse tipo de evento possivelmente provoca desestabilidade emocional e uma autopercepção de impotência, fazendo com que estes profissionais minimizem empatia pelos usuários como forma de defesa, assim configurando a Síndrome. A combinação dos dados neste estudo confirmou ligação desta variável com a SB.

No caso da APS carioca, atendendo o princípio da equidade, muitas equipes assistem áreas de grande vulnerabilidade social com a presença constante de indivíduos armados. O trabalho nestes territórios expõe o trabalhador muitas vezes à violência, acarretando a suspensão das atividades programadas, o que gera nos profissionais a sensação de não realização adequada do serviço $^{28}$. Esta dificuldade vivenciada pelos trabalhadores da APS foi descrita por Polaro ${ }^{29}$.

Este cenário compromete a saúde física e mental destes trabalhadores, além de levá-los a sentimentos de medo, de ansiedade, de impotência e de frustração. Lancman et al. ${ }^{29}$ acrescenta que, diante da violência armada, os profissionais se sentem expostos, e temendo por sua integridade física, preocupam-se com possíveis represálias e lamentam a invisibilidade dos esforços realizados. Este conjunto de fatores pode explicar a relação entre SB em gerentes da ESF e a presença de violência armada no território de atuação encontrada neste estudo.

Destaca-se o fato que, apesar de muitas equipes atuarem em território com presença de violência armada no país, ainda são raros os estudos que abordam o tema. Não foi possível localizar trabalhos que estudassem a relação entre presença de violência armada e a existência da Síndrome, possivelmente, porque os países que estudam a SB há mais tempo não convivem com esta experiência.

As características organizacionais foram as que apresentaram maior associação com a SB, corroborando com a visão de Maslach et al. ${ }^{13}$. Isto ocorre porque a organização espera que o empregado dedique cada vez mais tempo, esforço, talento e 
flexibilidade ao trabalho, sem ter que assegurar, de modo recíproco, oportunidades adequadas na carreira, estabilidade e segurança ${ }^{13}$.

Dentre as variáveis organizacionais a carga horária semanal de trabalho e o exercício laboral fora de horário pactuado não apresentaram associação com a SB. Para Schaufeli et al. ${ }^{16}$, no entanto, estes fatores estariam ligados à $\mathrm{SB}$, uma vez que não gozar de tempo suficiente para descansar e regenerar a energia reduzida, agrava o impacto da exaustão gerada pelo desiquilíbrio entre demanda e recursos disponíveis.

A percepção dos gerentes de que os prazos nem sempre são suficientes para a realização das tarefas propostas encontra ressonância no estudo de Maslach et al. ${ }^{13}$, que afirmam que a pressão por cumprimento de prazos é fortemente e consistentemente associadas a SB. O excesso de demanda e responsabilidade acima de sua capacidade, de modo rotineiro, contribui para que os profissionais desenvolvam uma sensação de incompetên$\mathrm{cia}^{13,28}$. Isto explica a associação identificada entre Burnout e gerentes da ESF que consideram os prazos insuficientes, e as demandas e as responsabilidades mais altas que sua capacidade.

A relação encontrada entre a síndrome e ausência de instrumentos de gestão disponíveis para apoiar o trabalho pode ser explicada de acordo com Maslach et al. ${ }^{13}$ pelo excesso de esforços para a realização das tarefas, o que induz os profissionais a exaustão. Do mesmo modo a associação com a falta de autonomia encontrada neste estudo é partilhada também por Trigo et al. ${ }^{27}$, que considera esta variável como um dos fatores explicativos de índices altos de Burnout. $\mathrm{O}$ trabalhador sente que tem grande responsabilidade, porém não possui autoridade para tomar as atitudes que julga eficaz, levando a um sentimento de incapacidade para gerar os resultados que lhe são exigidos e sensação de incompetên$\mathrm{cia}^{13}$.

Segundo Feliciano et al..$^{30}$, existe uma relação direta entre apoio organizacional e a SB. Esta associação foi demonstrada no presente estudo na combinação de dados. Chamou nossa atenção o fato de que entre os participantes com a SB o grau de confiança em seus apoiadores é baixo. Neste caso, a falta de confiança no suporte institucional pode trazer um efeito oposto ao qual este se propõe, gerando exaustão, frieza e insatisfação profissional. Segundo Maslach et al. ${ }^{13} \mathrm{o}$ suporte dos supervisores é especialmente mais importante até do que o apoio da equipe. Trigo et al. ${ }^{27}$ relata que quando o suporte organizacional é deficiente este provoca sensação de desamparo, desconfiança, desorientação e desrespeito.
Por outro lado, a baixa presença da Síndrome entre os profissionais que se sentem apoiados, pode indicar que o apoio institucional, quando é ofertado com regularidade, é capaz de gerar confiança, e, possivelmente servir como protetor quanto à SB para os gerentes. Conforme aponta Benevides-Pereira ${ }^{14}$, a existência de pessoas com quem se pode contar, confiar e refletir no ambiente ocupacional tem sido demonstrada por diversos estudos como possível forma de enfrentamento para a SB.

Da mesma forma a valorização profissional e a possibilidade de ascensão profissional são essenciais para o desenvolvimento de um bom trabalho. A sua ausência leva os profissionais à alta rotatividade no mercado de trabalho ${ }^{13,31} \mathrm{e}$ ao aumento das chances de desenvolvimento de exaustão emocional e de despersonalização ${ }^{31}$. Estes achados são semelhantes aos verificados neste estudo, onde a Síndrome se mostrou mais presente entre aqueles gerentes que não se consideraram valorizados e não acreditavam na possibilidade de crescimento profissional.

A ausência de associação entre estabilidade no emprego e SB merece destaque pois são elementos geradores de estresse. Uma possível explicação é a contradição que a existência de contratos especiais acarreta para o setor público. Segundo Victora et al. ${ }^{32}$ ao mesmo tempo em que estes contratos facilitam a admissão e demissão de funcionários, possibilita o pagamento de remunerações mais competitivas frente ao mercado de trabalho.

O Município do Rio de Janeiro, através de parceria estabelecida com as Organizações Sociais, paga aos profissionais terceirizados da APS salário superior ao recebido pelos servidores estatutários $^{33}$. Levantamos a hipótese de que este fato pode gerar uma compensação pela situação de instabilidade, igualando o peso destas variáveis e limitando seus efeitos na explicação dos fatores identificados pelos gerentes para o surgimento da síndrome.

Por outro lado, há um sentimento de que o salário do gerente não é justo dado à complexidade, relevância social do cargo, bem como, em comparação com o salário de outros profissionais, como por exemplo, os médicos, que são responsáveis por menores territórios e quantitativo populacional. Tal discrepância salarial foge a lei do mercado, onde maior competência profissional gera maior investimento financeiro para o seu pagamento ${ }^{6}$. Esta sensação de injustiça entre carga de trabalho e remuneração desigual é apontada por Maslach et al. ${ }^{13}$ como um dos fatores que contribuem para a Síndrome. 
As variáveis associadas estiveram, majoritariamente, relacionadas com questões organizacionais, indicando a necessidade de que a gestão municipal desenvolva medidas que sejam capazes de minimizar estes problemas, assegurar a saúde física e mental dos seus gerentes e promover o engajamento e satisfação destes profissionais com o trabalho ${ }^{12,34}$, reduzindo assim a possibilidade do profissional desenvolver Burnout ${ }^{35}$.

Para tal, é necessário reorganizar o processo de trabalho buscando adequar o volume de trabalho à carga horária e incentivar a formação de um ambiente de trabalho cooperativo e criativo, com o estabelecimento de mecanismos de recompensas e reconhecimentos justos e adequados, para que os profissionais se sintam valorizados e satisfeitos ${ }^{7,13}$.

Os gerentes da Estratégia de Saúde da Família estão imersos em um território que produz e reproduz relações de poder e de produção de sujeitos, o que exige destes profissionais a compreensão dos processos políticos, sociais e culturais nos quais seu território está envolto. Isto coloca para estes profissionais vários conflitos, inclusive ideológicos ${ }^{36}$, causando, muitas vezes, sofrimento e insatisfação, tendo em vista a dissonância entre as expectativas e a realidade imposta pela organização do trabalho.

Neste contexto a oferta de processos formativos permanente é um mecanismo fundamental, pois possibilita aos profissionais, em conjunto, a produção de reflexão e novos significados para o trabalho, em sua complexidade e contradições, o que pode contribuir para uma gestão mais integrada e o maior engajamento profissional ${ }^{12,34}$.

Essas questões não podem ser compreendidas dissociadas dos efeitos das transformações do mundo do trabalho sobre o trabalho em saúde, marcada pela precarização das relações de trabalho na ESF e, que segundo diversos autores ${ }^{37,38}$ têm na fragilidade dos vínculos empregatícios e nas mudanças na organização e no sentido do trabalho sua face mais visível.

Diante deste quadro, sugere-se que novos estudos sejam realizados a fim de melhor compreender a síndrome neste grupo específico. Um aspecto importante neste processo é o de entender as consequências da violência armada no território sobre a saúde dos profissionais da ESF e para as práticas de saúde, tendo em vista que estas não estão dissociadas da forma de reprodução da sociedade $^{38}$. Estes esforços poderiam embasar a implementação de medidas de prevenção e o desenvolvimento de um plano de intervenção para aqueles já acometidos por Burnout.

Por fim cabe salientar as limitações deste estudo: a primeira, diz respeito à dificuldade de comparar os resultados encontrados com a literatura, seja pela forma como os autores optaram por apresentar os dados, expondo somente resultados referentes às dimensões da $\mathrm{SB}$, seja pela variedade de escalas existentes para a identificação da síndrome ou pela variação entre os pontos de corte. A não identificação de estudos efetuados com gerentes de ESF/APS também dificultou a comparação.

Outra limitação se refere aos respondentes, apenas $63,5 \%$ dos gerentes responderam ao questionário. É possível que aqueles que se sintam saudáveis, não tenham tido interesse em participar da pesquisa, por não vislumbrarem benefícios na sua participação, o que pode ter influenciado no resultado da pesquisa. Por fim, estudos seccionais são retratos do momento, não possibilitando a compreensão do comportamento da Síndrome ao longo do tempo.

\section{Colaboradores}

AM Porciuncula trabalhou em toda concepção e redação final. SA Venâncio trabalhou na concepção e redação final. CMFP Silva trabalhou na metodologia, resultados e redação final. 


\section{Referências}

1. Portela GZ, Ribeiro JM. A reforma da Atenção Primária à Saúde e a utilização dos serviços ambulatoriais no município do Rio de Janeiro (RJ), Brasil. Saúde Debate 2016; 40(111):34-48

2. Soranz D, Pinto LF, Penna GO. Eixos e a Reforma dos Cuidados em Atenção Primária em Saúde (RCAPS) na cidade do Rio de Janeiro, Brasil. Cien Saude Colet 2016; 21(5):1327-1338.

3. Bloise MS. Os Gerentes de Unidades Básicas de Saúde do município do Rio de Janeiro: perfil, vivências e desafios. [dissertação]. Rio de Janeiro; Escola Nacional de Saúde Pública; 2015.

4. Pêssoa L, coordenadora. Manual do Gerente: desafios da média gerência na saúde. ENSP. Rio de Janeiro, 2011.

5. Brasil. Ministério da Saúde (MS). Norma operacional básica do Sistema Único de Saúde/NOB-SUS 96. Brasília: MS; 1997.

6. Ximenes Neto FRG, Sampaio JJC. Gestores do território na Estratégia Saúde da Família: análise e perfil de necessidades de qualificação. Rev Bras Enferm 2007; 60(6):587-595.

7. Mesquita DT, Ximenes Neto FRG, Moreira ACA. Satisfação profissional do gerente na ESF. Rev Adm Saude 2013; 15(59):63-70.

8. Organização Pan-Americana da Saúde (OPAS). Renovação da Atenção Primária em Saúde nas Américas: documento de posicionamento da Organização PanAmericana da Saúde/Organização Mundial da Saúde (OPAS/OMS). Washington: OPAS; 2007.

9. Codo W, Vasques-Menezes I. O que é Burnout. In: Codo W, organizador. Educação: carinho e trabalho. Petrópolis: CNTE; 1999. p. 237-254.

10. Tamayo MR, Tróccoli BT. Exaustão emocional: Relações com a percepção de suporte organizacional e com as estratégias de coping no trabalho. Estudos Psicol 2002; 7(1):37-42.

11. Albuquerque FJB, Melo CF, Araujo Neto JL. Avaliação da síndrome de burnout em profissionais da Estratégia Saúde da Família da capital paraibana. Psicologia Reflexão Critica 2012; 25(3) 542-549.

12. Barroso SM, Guerra ARP. Burnout e qualidade de vida de agentes comunitários de saúde de Caetanópolis (MG). Cad Saude Colet 2013; 21(3):338-345.

13. Maslach C, Schaufeli WB, Leiter MP. Job Burnout. Annual Review Pscycol 2001: 52:397-422

14. Benevides-Pereira AMT. O processo de adoecer no trabalho. In: Pereira AMB organizador. Burnout: Quando o trabalho ameaça o bem-estar do trabalhador. São Paulo: Casa do Psicólogo; 2002. p. 21-91

15. Maslach C, Jackson SE. The measurement of experienced burnout. J Occup Behavior 1981; 2:99-113.

16. Schaufeli WB, Leiter MP, Maslach C. Burnout: 35 years of research and practice. Career Development International 2008; 14(3):204-220.

17. Moreno FN, Gil GP, Haddad MCL, Vannuchi MTO. Estratégias e intervenções na Síndrome de Burnout. Rev Enferm UERJ 2011; 19(1):140-145.
18. Brasil. Ministério da Saúde (MS). Organização Pan -Americana da Saúde no Brasil (OPAS). Doenças relacionadas ao trabalho: manual de procedimentos para os serviços de saúde. Brasília: MS; 2001. (Série A. Normas e Manuais Técnicos; n.114).

19. Zorzanelli R, Vieira I, Russo JA. Diversos nomes para o cansaço: categorias emergentes e sua relação com o mundo do trabalho. Interface (Botucatu) 2016; 20(56):77-88.

20. Mota CM, Dosea GS, Nunes PS. Avaliação da presença da Síndrome de Burnout em Agentes Comunitários de Saúde no município de Aracaju, Sergipe, Brasil. Cien Saude Colet 2014; 19(12):4719-5726.

21. Silva SCPS, Nunes MAP, Santana VR, Reis FP, Machado Neto J, Lima SO. A síndrome de burnout em profissionais da Rede de Atenção Primária à Saúde de Aracaju, Brasil. Cien Saude Colet 2015; 20(10):30113020.

22. Carlotto MS, Câmara SG. Análise fatorial do Malasch Burnout Inventory (MBI) em uma amostra de professores de instituições particulares. Psicol Estudos 2004; 9(3):499-505.

23. Ramirez AJ, Graham J, Richards MA, Cull A, Gregory WM. Mental health of hospital consultants: the effects of stress and satisfaction at work. Lancet 1996; 347:724-728

24. Trindade LL, Lautert L, Beck CLC, Amestoy SC, Pires DEP. Estresse e síndrome de burnout entre trabalhadores da ESF. Acta paul Enferm 2010; 23(5): 684-689.

25. Silveira SLM, Câmara SG, Amazarray MR. Preditores da Síndrome de Burnout em profissionais da saúde na atenção básica de Porto Alegre/RS. Cad Saude Colet 2014; 22(4):386-392.

26. Poletto NA, Probst LF, Oliveira TL, Guerra LM, Ambroosano GMB, Cortellazi KL, Gil-Monte PR, Possobon RF. Síndrome de Burnout em gestores municipais da saúde. Cad Saude Colet 2016; 24(2):209-215.

27. Trigo TR, Teng CT, Hallar JEC. Síndrome de Burnout ou estafa profissional e os transtornos psiquiátricos. Rev Psiq Clin 2007; 34(5):223-233.

28. Polaro SHI, Goncalves LHT, Alvarez AM. Enfermeiras desafiando a violência no âmbito de atuação da ESF. Texto Contexto Enferm 2013; 22(4):934-942.

29. Lancman S, Ghirardi MIG, Castro ED, Tuacek TA. Repercussões da violência na saúde mental de trabalhadores do Programa Saúde da Família. Rev Saude Publica 2009; 43(4):682-688

30. Feliciano KVO, Kovacs MH, Sarinho SW. Burnout entre médicos da Saúde da Família: os desafios da transformação do trabalho. Cien Saude Colet 2011; 16(8):3373-3382.

31. Sa AMS, Martins-Silva PO, Funchal B. Burnout: o impacto da satisfação no trabalho em profissionais de enfermagem. Psicol Soc 2014 26(3): 664-674.

32. Victora CG, barreto ML, Leal MC, Monteiro CA, Schimidt MI, Paim JS, Almeida CM, bastos FIPM, Bahia L, Travassos CMR, Reichenheim M, Barros FC. Condições de saúde e inovações nas políticas de saúde no Brasil: o caminho a percorrer. Lancet 2011; 6:90-102. 
33. Magnago C, Pierantoni CR. Dificuldades e estratégias de enfrentamento referentes à gestão do trabalho na Estratégia Saúde da Família, na perspectiva dos gestores locais: a experiência dos municípios do Rio de Janeiro (RJ) e Duque de Caxias (RJ). Rev Saude Debate 2015; 39(104):9-17.

34. Porto-Martins PC, Basso-Machado PG, Benevides -Pereira AMT. Engagement no trabalho: uma discussão teórica. Fractal Rev Psicol 2013; 25(3):629-644.

35. Hoppen CMS, Kissman N, Chinelato JR, Coelho VP, Wenczenovicz C, Nunes FCL, Friedman G. Alta prevalência de síndrome de burnout em médicos intensivistas da cidade de Porto Alegre. Rev Bras Ter Intensiva $2017 ; 29(1): 115-120$.

36. Ximenes Neto FRG, Sampaio JJC. Análise do processo de trabalho dos gerentes no território da Estratégia Saúde da Família. Rev Gerenc Polit Salud Bogotá (Colombia) 2012; 11(22):76-91.

37. Rizzo TP, Lacaz FAC. Limites dos planos de cargos, carreiras e salários para desprecarização das relações de trabalho no SUS. Trabalho Educ Saude 2017; 15(2):399-420.

38. Schimith MD, Brêtas ACP, Simon BS, Brumd JT, Alberti GF, Bidó MLD, Gomes TF. Precarização e fragmentação do trabalho na Estratégia de Saúda da Família: impactos em Santa Maria (RS). Trabalho Educ Saude 2017; 15(1):163-182.

Artigo apresentado em 21/03/2017

Aprovado em 05/09/2018

Versão final apresentada em 07/09/2018 
